\title{
Early morphological processing is morphosemantic and not simply morpho-orthographic: A violation of form-then-meaning accounts of word recognition
}

\author{
LAURIE BETH FeLdMAN \\ University at Albany, State University of New York, Albany, New York \\ and Haskins Laboratories, New Haven, Connecticut \\ Patrick A. O'CONNOR \\ University at Albany, State University of New York, Albany, New York
}

AND

Fermín Moscoso del Prado Martín

CNRS and Université de Provence, Marseille, France

\begin{abstract}
Many studies have suggested that a word's orthographic form must be processed before its meaning becomes available. Some interpret the (null) finding of equal facilitation after semantically transparent and opaque morphologically related primes in early stages of morphological processing as consistent with this view. Recent literature suggests that morphological facilitation tends to be greater after transparent than after opaque primes, however. To determine whether the degree of semantic transparency influences parsing into a stem and a suffix (morphological decomposition) in the forward masked priming variant of the lexical decision paradigm, we compared patterns of facilitation between semantically transparent (e.g., coolant-COOL) and opaque (e.g., rampant-RAMP) primetarget pairs. Form properties of the stem (frequency, neighborhood size, and prime-target letter overlap), as well as related-unrelated and transparent-opaque affixes, were matched. Morphological facilitation was significantly greater for semantically transparent pairs than for opaque pairs. Ratings of prime-target relatedness predicted the magnitude of facilitation. The results limit the scope of form-then-meaning models of word recognition and demonstrate that semantic similarity can influence even early stages of morphological processing.
\end{abstract}

A common assumption in models of word recognition is that a word's orthographic form must be processed before its meaning can become available. With respect to morphology, researchers typically assume that later stages of word recognition are influenced by semantic properties of the stem but that initial stages are solely orthographic. Thus, the failure to detect differing magnitudes of facilitation for whiter-WHITE (semantically similar) and for corner-CORN (semantically dissimilar) prime-target pairs when primes are forward masked at short stimulus onset asynchronies (SOAs) provides primary support for an early morphoorthographic stage in models of morphological processing in English (for a review, see Rueckl \& Aicher, 2008). A meta-analytic review of these priming effects, however, raises the possibility of very early semantic effects insofar as morphological facilitation is slightly greater after transparent (semantically similar) than after opaque (semantically dissimilar) primes. Collectively, the results demonstrate the risk of using a (null) finding about differing facilitation after semantically transparent and opaque morphologically related primes to claim that parsability of a word's orthographic structure into a stem and an affix is devoid of morphosemantic structure (see Table 1).

Limits on the form-then-meaning assumption are not limited to morphological models of word recognition. Near simultaneous access to the orthophonological and semantic properties of words is central to some current neurophysiological theories of lexical processing. For instance, Pulvermüller, Assadollahi, and Elbert (2001) and Pulvermüller, Shtyrov, and Ilmoniemi (2003) reported that all of the cortical subnetworks (including semantic aspects) related to the processing of a word automatically fire with the activation of the subnetworks that encode orthographic and/or phonological forms of the words. In essence, early access to the semantic properties of words does not seem to be a peculiarity of masked priming in the

L. B. Feldman, If503@albany.edu 
Table 1

Summary of Published Early Semantic Transparency Effects in the Masked Priming Paradigm As Reviewed by Rastle and Davis (2008)

\begin{tabular}{|c|c|c|c|}
\hline \multirow[b]{2}{*}{ Study } & \multirow{2}{*}{$\begin{array}{l}\text { Prime } \\
\text { Duration } \\
(\mathrm{msec})\end{array}$} & \multicolumn{2}{|c|}{ Facilitation (msec) } \\
\hline & & Transparent & Opaque \\
\hline Kazanina, Dukova-Zheleva, Geber, Kharlamov, \& Tonciulescu (2008) & 59 & 44 & 51 \\
\hline Marslen-Wilson, Bozic, \& Randall (2008) & 36 & 18 & 21 \\
\hline Marslen-Wilson et al. (2008) & 48 & 36 & 23 \\
\hline McCormick, Rastle, \& Davis (2008, Experiment 4) & 42 & 20 & 18 \\
\hline Lavric, Clapp, \& Rastle (2007) & 42 & 32 & 25 \\
\hline Morris, Frank, Grainger, \& Holcomb (2007)* & 50 & 43 & 27 \\
\hline Diependaele, Sandra, \& Grainger (2005) & 40 & 21 & -8 \\
\hline Diependaele et al. $(2005)^{*}$ & 53 & 26 & -2 \\
\hline Devlin, Jamison, Matthews, \& Gonnerman (2004) & 33 & 26 & 25 \\
\hline Feldman, Soltano, Pastizzo, \& Francis (2004) & 48 & 14 & 20 \\
\hline Feldman et al. (2004) & 83 & 22 & 15 \\
\hline Rastle, Davis, \& New (2004) & 42 & 27 & 22 \\
\hline Longtin, Segui, \& Halle $(2003)^{\dagger}$ & 46 & 38 & 35 \\
\hline Rastle \& Davis (2003, Experiment 1A) & 52 & 40 & 41 \\
\hline Rastle \& Davis (2003, Experiment 2) & 52 & 30 & 22 \\
\hline Rastle, Davis, Marslen-Wilson, \& Tyler (2000) & 43 & 46 & 35 \\
\hline Rastle et al. $(2000)$ & 72 & 61 & 16 \\
\hline Feldman \& Soltano (1999) & 48 & 19 & 23 \\
\hline
\end{tabular}

*These studies included an additional backward mask that separated prime and target. TOpaque reaction times were averaged across the opaque and pseudosuffixed conditions in this study. $\$$ Not included in Rastle and Davis (2008).

lexical decision paradigm. Rather, it seems to be a general property of the system.

Evidence that the degree of similarity between the meanings of morphologically complex primes and their stems influences the magnitudes of morphological facilitation has been frequently documented with unmasked primes in Dutch (Diependaele, Sandra, \& Grainger, 2005) and Serbian (Feldman, Barac-Cikoja, \& Kostić, 2002), as well as English (Feldman \& Soltano, 1999; Marslen-Wilson, Tyler, Waksler, \& Older, 1994) and Hebrew (Bentin \& Feldman, 1990). Semantic influences on morphological processing when primes are masked and/or appear at SOAs shorter than $60 \mathrm{msec}$ have been more elusive, however. Early researchers failed to observe reliable effects of semantic transparency (Longtin, Segui, \& Halle, 2003; Rastle, Davis, \& New, 2004), but recent results are more equivocal. Diependaele et al. (2005) demonstrated differing time courses in Dutch for effects of transparent and opaque primes using the incremental priming technique (Jacobs, Grainger, \& Ferrand, 1995). Similarly, in French, semantically transparent morphological primes appearing for $40 \mathrm{msec}$ produced facilitation, whereas opaque primes facilitated only at $67 \mathrm{msec}$. Finally, in English, MarslenWilson, Bozic, and Randall (2008) and Lavric, Clapp, and Rastle (2007) observed numerically greater facilitation after transparent primes than after opaque primes. Many individual studies show statistically nonsignificant differences in the magnitude of facilitation for transparent and opaque prime-target pairs. Although unwarranted, this lack of evidence is often taken as support for the null hypothesis. Nonetheless, collectively, these nonsignificant differences are remarkably consistent: There is more facilitation for semantically related than for opaque pairs. A paired $t$ test on the means from the 16 published experiments that manipulated semantic transparency with masked morpho- logical primes and SOAs shorter than $60 \mathrm{msec}$ reviewed by Rastle and Davis (2008) confirms this pattern (see Table 1). Across studies, facilitation is, in fact, significantly greater after transparent than after opaque primes $[t(15)=2.34$, $p=.03$, two-tailed]. Because, with a small sample, it is difficult to ascertain that the data are normally distributed, we also confirmed this result by a nonparametric Wilcoxon signed rank test $[V=106.5, p=.049$, two-tailed].

In light of this misreading of the literature regarding the early effects of semantic transparency and the relevance of this misinterpretation for models that assume the analysis of form before the analysis of meaning, in the present study, we compared morphological facilitation after transparent primes with that after opaque primes. It differs from previous studies in two potentially important ways. Each may enhance the possibility of observing an effect that reaches significance in an individual experiment. Some affixes can alter the semantic (and phonological) contribution of the stem to the meaning (or form) of the complex form produced by their combination (Bertram, Schreuder, \& Baayen, 2000). For example, -ER is a highly productive affix, since it combines with many different stems. When it combines with WHIT(E) to form a comparative adjective (WHITER) and when it combines with BEEP to form an agentive noun (BEEPER), the outcomes are morphologically complex words that are relatively transparent semantically, phonologically, and orthographically. By contrast, if -ER in CORNER is an affix, its stem (CORN) must be semantically opaque, although it preserves its form. In addition, some affixes can combine with many stems; others, like -ILE, combine with relatively few stems, so it is not universally accepted that they are English suffixes. Across affixes, combinatorial consequences for the transparency of stems vary in a graded manner, as do the number of stems with which each affix combines. Thus, affixes, like stems, have their own combinatorial charac- 
teristics, and such item variability may affect processes of word recognition (Baayen, 2007b; Baayen, Wurm, \& Aycock, 2007). In the present study, therefore, we matched affixes across semantically transparent and opaque related (and unrelated) prime-target pairs to investigate whether morpho-orthographic parsability is sufficient to account for the observed patterns of morphological facilitation.

Morphological (e.g., artist-ART) facilitation is robust when primes are forward masked and appear in the primed lexical decision paradigm for durations of $48 \mathrm{msec}$ (Forster \& Azuma, 2000; Forster, Davis, Schoknecht, \& Carter, 1987; Rastle, Davis, Marslen-Wilson, \& Tyler, 2000). By comparison, semantic (e.g., craft-ART) facilitation is rarely reliable in this paradigm (Forster, Mohan, \& Hector, 2003; Rastle et al., 2000). Nonetheless, when experimental lists contain a high proportion of identical (ID) prime-target filler trials (e.g., artist-ARTIST), semantic facilitation has been documented even when the primes are forward masked (Bodner \& Masson, 2003). In fact, increasing the listwide relatedness proportion to $75 \%$ by the inclusion of form-similar word-word and word-nonword ID trials significantly boosts both semantic and morphological facilitation (Feldman \& Basnight-Brown, 2008). Therefore, in the present study, we introduced many ID filler trials and concomitant listwise semantic similarity so as to maximize the evidence of morphological processing and the potential to detect an interaction with semantic transparency in the forward masked primed lexical decision task.

\section{METHOD}

\section{Participants}

Eighty-eight students from the University at Albany participated in partial fulfillment of the introductory psychology course requirements. All of them were monolingual English speakers with normal or corrected-to-normal vision and with no known reading or speech disorders.

\section{Materials}

Eighty stems were selected as critical word targets. Half of these appeared with a semantically transparent derivationally related prime, and half appeared with a semantically opaque derivationally related prime. The unrelated primes did not share a stem with their targets ${ }^{1}$ but always included the same affix as the related prime for a given target. In the semantically transparent condition, the targets were morphological stems (e.g., TOUGH), and the related primes (e.g., toughen) retained their meaning. In the semantically opaque condition, targets (e.g., BEAK) also appeared in their primes, but the related primes (e.g., beaker) failed to retain the stem meaning. Unrelated primes (e.g., gladden, dryer) for both target types retained the affix of the related prime. The semantically opaque related condition included both semantically opaque primes, which were related etymologically to the target (e.g., dentist-DENT), and truly pseudomorphemic primes (e.g., cower-COW), because previous studies have concluded that parsability into a stem and an affix, rather than a linguistically defined morphological relation between the prime and the target, determine the patterns of facilitation in this task (Diependaele et al., 2005; Longtin et al., 2003; Rastle et al., 2004).

The 40 targets in the semantically transparent and semantically opaque stem sets were closely matched with respect to variables known to influence decision latencies. These include length, frequency (Kučera \& Francis, 1967), logged Usenet frequencies in the HAL system (Lund \& Burgess, 1996), orthographic neighborhood size, phonological neighborhood size, and normed single word lexical decision reaction time (RT; Balota et al., 2007). Table 2 summarizes the means and standard deviations for these attributes for the 72 items that were included in the present analyses. The primes for the semantically transparent related targets retained the meaning of the stem, whereas the primes for the opaque related targets did not retain the same meaning as the target word. The difference in preservation of meaning across the two target types is reflected in latent semantic analysis (LSA) cosine values (Landauer, Foltz, \& Laham, 1998), which reflect the extent to which the words may be used in the same context and rating judgments based on a 7-point scale $[t(56)=$ 4.91, $S E_{\text {diff }}=0.05$, and $t(70)=16.67, S E_{\text {diff }}=0.19, p \mathrm{~s}<.005$, respectively]. The participants performed a rating task ${ }^{2}$ to assess semantic transparency for the present items and those used by Rastle et al. (2004). Independent $t$ tests indicated that transparency differed significantly between the two sets of opaque items ( 2.34 vs. 2.73$)$ $\left[t(85)=1.91, S E_{\text {diff }}=0.18, p=.059\right]$. The transparent items did not differ significantly $\left[t(88)=0.13, S E_{\text {diff }}=0.21, p=.90\right]$. Stated succinctly, the items in the present study capture a stronger manipulation of transparency than do those items used by Rastle et al. (2004). Finally, we matched the number of (related and unrelated) primes with a particular affix for the semantically transparent and the opaque stems (e.g., three transparent and three opaque stems had primes ending in -ABLE, one transparent and one opaque stem had

Table 2

Mean Values and Standard Deviations (SDs) for Item Attributes As a Function of Stem Type

\begin{tabular}{|c|c|c|c|c|c|c|c|c|c|c|c|c|}
\hline \multirow[b]{4}{*}{ Variable } & \multirow{2}{*}{\multicolumn{4}{|c|}{ Stem Type }} & \multicolumn{8}{|c|}{ Prime Type } \\
\hline & & & & & \multicolumn{4}{|c|}{ Transparent Stem } & \multicolumn{4}{|c|}{ Opaque Stem } \\
\hline & \multicolumn{2}{|c|}{ Transparent } & \multicolumn{2}{|c|}{ Opaque } & \multicolumn{2}{|c|}{ Related } & \multicolumn{2}{|c|}{ Unrelated } & \multicolumn{2}{|c|}{ Related } & \multicolumn{2}{|c|}{ Unrelated } \\
\hline & $M$ & $S D$ & $M$ & $S D$ & $M$ & $S D$ & $M$ & $S D$ & $M$ & $S D$ & $M$ & $S D$ \\
\hline Length & 4.08 & 0.70 & 4.00 & 0.71 & 6.69 & 1.10 & 7.03 & 0.93 & 6.94 & 1.06 & 6.88 & 0.96 \\
\hline $\mathrm{K}-\mathrm{F}$ frequency & 30.13 & 28.70 & 30.91 & 43.92 & 16.44 & 24.36 & 7.48 & 8.58 & 18.96 & 25.48 & 9.14 & 13.71 \\
\hline Logged HAL frequency & 3.73 & 0.70 & 3.77 & 0.74 & 2.58 & 0.99 & 2.75 & 0.67 & 2.97 & 0.99 & 2.94 & 0.74 \\
\hline Orthographic $N$ & 11.46 & 6.31 & 12.18 & 7.41 & & & & & & & & \\
\hline Phonological $N$ & 23.08 & 15.66 & 24.85 & 16.60 & & & & & & & & \\
\hline ELP lexical decision RT (msec) & 638 & 65 & 637 & 59 & & & & & & & & \\
\hline LSA $^{*}$ & 0.31 & 0.22 & 0.09 & 0.09 & & & & & & & & \\
\hline Mean relatedness rating* & 5.62 & 0.87 & 2.41 & 0.74 & & & & & & & & \\
\hline Morph family size ${ }^{\dagger}$ & 4.46 & 4.43 & 2.59 & 3.28 & & & & & & & & \\
\hline Number of spelling changes & 11 & & 12 & & & & & & & & & \\
\hline Number of sound changes & 5 & & 4 & & & & & & & & & \\
\hline
\end{tabular}

Note-These data reflect only those items included in the analyses. K-F, Kučera and Frances (1967); ELP, English Lexicon Project; LSA, latent semantic analysis. "Significant difference between stem types, $p<.0005$. †Marginally significant difference between stem types, $p=.057$. 
primes ending in -IST, etc.). For most of the pairs, the stem's spelling and pronunciation were retained in the prime. Although purported not to influence facilitation (McCormick, Rastle, \& Davis, 2008), instances of spelling or sound mismatch (huskiness-HUSK) were equated across the semantically transparent and opaque stems (see Table 2). (See Appendix.)

\section{Design}

Each target appeared with either a related or an unrelated prime for each participant. Across participants, all targets were preceded equally often by related and unrelated primes. Each participant responded to 20 trials in each condition created by the 2 (stem type: transparent vs. opaque) $\times 2$ (relatedness: related vs. unrelated) design.

In addition to the 80 critical items described above, 50 word-word pairs were included as filler stimuli. All of the word-word filler pairs had identical primes and targets (i.e., ID trials). Half of these were morphologically simple words (e.g., note-NOTE), and the other half included an affix and were thus complex (e.g., sticker-STICKER). Each participant responded to 130 word target trials in total. In order to make the relation between form overlap and target lexicality uninformative (cf. Rastle et al., 2004), the 130 word-nonword pairs were either related, in that the prime word contained the nonword target's form plus a frequent letter sequence as the ending (e.g., fertile-FERT), or unrelated, in that the prime and target shared no letters in the same position. All of the filler trials were identical across counterbalancing lists.

\section{Procedure}

Each trial began with a $500-m s e c$ fixation point $(+)$ that appeared in the middle of the screen. An interstimulus interval of $50 \mathrm{msec}$ occurred before the forward mask (\#\#\#\#), which lasted $450 \mathrm{msec}$. The number of pound signs (\#) in the forward mask matched the number of letters in the prime. The prime then appeared in lowercase letters for $50 \mathrm{msec}$ and replaced the mask. The target was printed in capital letters and replaced the prime in the same position. The targets were visible for 3,000 msec or until the participant made a response. The intertrial interval was $1,000 \mathrm{msec}$.

The items were presented on a G3 Macintosh computer in black 16-point font on a white background. A different random order of prime-target pairs appeared for each participant. The participants made a lexical decision for each target on a PsyScope button box by pressing the right button (green) for words and the left button (red) for nonwords. The participants responded to 12 practice trials before the experimental session, and the makeup of the practice stimuli mirrored that of the stimuli in the main experiment.

\section{RESULTS AND DISCUSSION}

The overall mean accuracy rates for each participant and each item on the critical trials were computed, and the data from 1 participant and five items were discarded because of error rates greater than $30 \%$. For the RT analyses, all trials with incorrect responses ( $6.6 \%$ of the total) and trials with RTs greater than $1,800 \mathrm{msec}(0.8 \%$ of the total correct trials) were trimmed. The remaining correct RTs were logtransformed to better approximate normality and homoscedasticity. ${ }^{3}$ The main analyses on RTs consisted of $2 \times$ 2 repeated measures ANOVAs for the participant $\left(F_{1}\right)$ data and 2 (stem type: transparent vs. opaque, between items) $\times$ 2 (relatedness: related vs. unrelated, within items) mixed ANOVAs for the item $\left(F_{2}\right)$ data $(p$ s $<.05$ unless otherwise specified; see Table 3). In addition, we confirmed these results using the more recent linear mixed effect model methodology (cf. Baayen, Davidson, \& Bates, 2008; Milin, Filipović Durdević, \& Moscoso del Prado Martín, 2009). ${ }^{4}$
Table 3

Participant Means, Standard Deviations, and Simple Facilitation Effects for Reaction Times (RTs, in Milliseconds) and Percentages of Error (PEs) As a Function of Prime and Stem Type

\begin{tabular}{|c|c|c|c|c|c|c|c|c|}
\hline \multirow[b]{4}{*}{ Prime Type } & \multicolumn{8}{|c|}{ Stem Type } \\
\hline & \multicolumn{4}{|c|}{ Transparent } & \multicolumn{4}{|c|}{ Opaque } \\
\hline & \multicolumn{2}{|c|}{ RT } & \multicolumn{2}{|c|}{$\mathrm{PE}$} & \multicolumn{2}{|c|}{ RT } & \multicolumn{2}{|c|}{$\mathrm{PE}$} \\
\hline & $M$ & $S D$ & $M$ & $S D$ & $M$ & $S D$ & $M$ & $S D$ \\
\hline Unrelated & 632 & 94 & 6.0 & 0.07 & 652 & 100 & 6.8 & 0.09 \\
\hline Related & 602 & 84 & 5.1 & 0.06 & 648 & 103 & 8.7 & 0.08 \\
\hline Facilitation & $30^{*}$ & & 0.9 & & 4 & & -1.9 & \\
\hline
\end{tabular}

Note-RTs in the table were converted from the log-transformed RTs used in the data analyses. ${ }^{*} p<.05$.

The analyses on the $\log$ RT data revealed a significant main effect of stem type $\left[F_{1}(1,86)=49.25, M S_{\mathrm{e}}=0.001\right.$; $\left.F_{2}(1,70)=6.71, M S_{\mathrm{e}}=0.003\right]$, a significant main effect of relatedness $\left[F_{1}(1,86)=20.02, M S_{\mathrm{e}}=0.001 ; F_{2}(1,70)=\right.$ $\left.22.69, M S_{\mathrm{e}}<0.001\right]$, and-most important-a significant stem type $\times$ relatedness interaction $\left[F_{1}(1,86)=8.08\right.$, $\left.M S_{\mathrm{e}}=0.001 ; F_{2}(1,70)=8.49, M S_{\mathrm{e}}<0.001\right]$. The main effect of stem type indicated that semantically transparent stems were responded to more quickly than were opaque stems, and the main effect of relatedness indicated that related pairs were responded to more quickly than were unrelated pairs (facilitation). Finally, despite matching on multiple measures of form overlap between the prime and the target and between target properties for the two stem types, the two-way interaction and comparisons indicated that facilitation $(30 \pm 11 \mathrm{msec})$ for semantically transparent stems $\left[t_{1}(86)=5.64, S E M=0.004, p<.0005\right.$; $\left.t_{2}(38)=5.65, S E M=0.004, p<.0005\right]$ was robust, whereas facilitation $(4 \pm 13 \mathrm{msec})$ for opaque stems was not statistically reliable $\left[t_{1}(86)=0.66, S E M=0.004, p=\right.$ $\left..52 ; t_{2}(33)=1.26, S E M=0.004, p=.22\right]$. Not surprising, the effect of transparency on facilitation remained when pairs that underwent spelling or sound change were deleted. Collectively, the RT data for both participants and items converge on the same conclusion: Facilitation was robust for transparent pairs, but smaller in magnitude and not reliable for opaque pairs. ${ }^{5}$

A logistic mixed model regression was fitted to the counts of correct and incorrect responses with fixed effects of $\log$ target frequency, $\log$ family size, relatedness (related vs. unrelated), stem type (transparent vs. opaque, nested under relatedness), and random effects of participant and target identity. The model revealed significant main effects of frequency $[\beta=-0.2717, z=-2.6896, p=.0072]$ and family size $[\beta=-0.3636, z=-2.0156, p=.0438]$. The effect of relatedness was not significant. The interaction of relatedness and stem type indicated fewer errors for transparent $[\beta=-0.5591, z=-2.0334, p=.0420]$ than for opaque $[z=-0.3643, p=.7156]$ stems.

In summary, transparent primes produce greater facilitation than do opaque primes. With few exceptions (e.g., Moscoso del Prado Martín, 2007; Plaut \& Gonnerman, 2000), models of visual word recognition typically posit independent and sometimes rate varying morphosemantic and morpho-orthographic processes. In the present study, 
interactions of meaning with form activation call into question the autonomy of morpho-orthographic from morphosemantic processing and the universality of the form-thenmeaning assumption within models of word recognition.

Even when the published differences in amount of facilitation between semantically transparent and semantically opaque morphologically related primes are small and do not reach significance in individual experiments, the trend throughout is that semantically transparent pairs produce greater facilitation than do semantically opaque ones. In this respect, our result statistically confirms a pattern that is present overall in the literature. As is evident in
Figures $1 \mathrm{~A}-1 \mathrm{D}$, the present data (crosses) failed to differ from those in the published literature (circles). The contour lines represent a Gaussian kernel density estimate of the probability of finding points in different parts of the space. In fact, one would conclude that the present data are nearly prototypical of the published literature; relative to the collective literature, it is not possible to claim that there is something strange in the present data. If one were to exclude experiments that deviate from the overall pattern, one would exclude not the present study but, rather, the data of Feldman, Soltano, Pastizzo, and Francis (2004), where latencies were atypically slower, as well as those from both
A

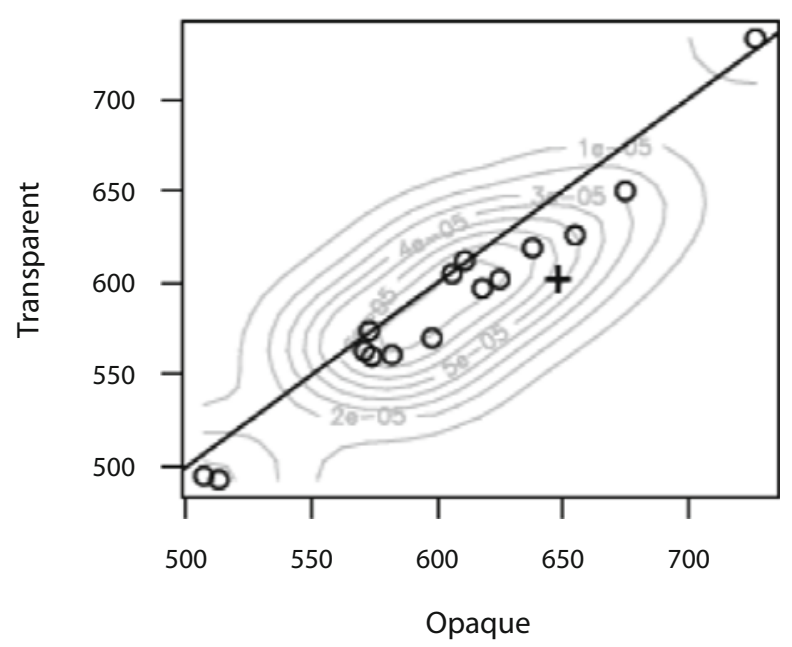

C

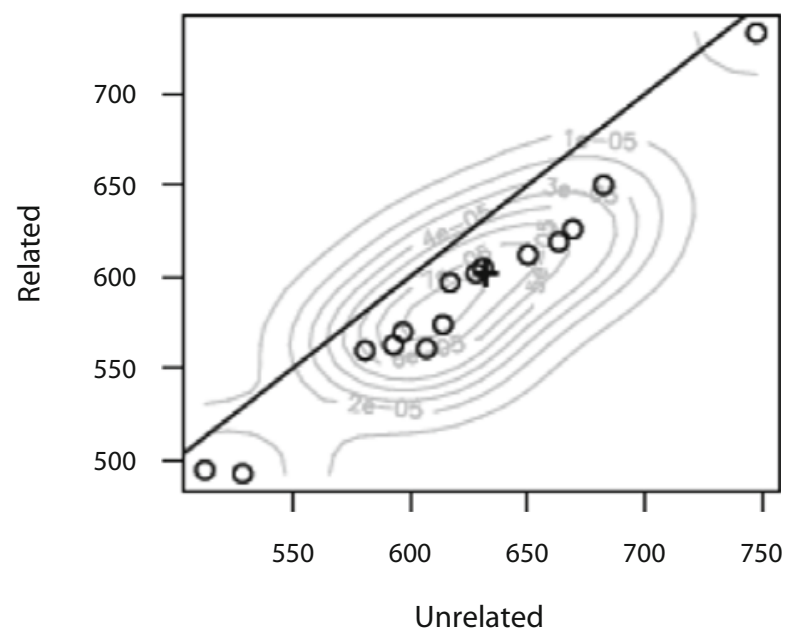

B

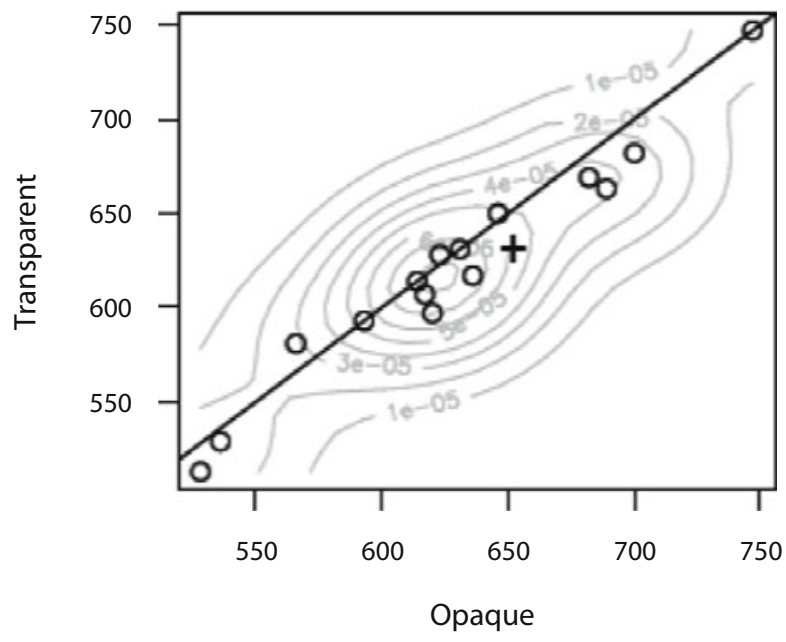

D

Opaque

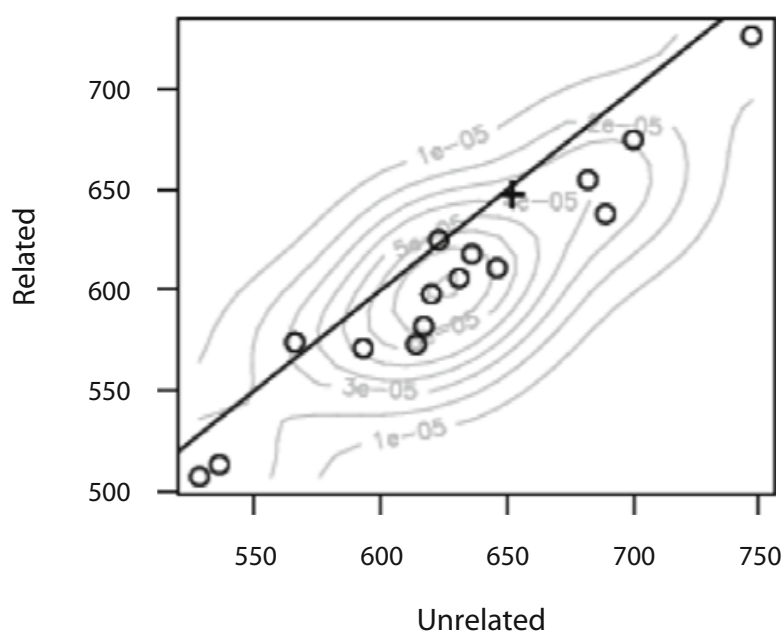

Figure 1. Summary of the published evidence on morphological priming for short stimulus onset asynchronies. The panels plot the reaction times (RTs, in milliseconds) in the present study (crosses) in the context of the 16 previously published studies for which the RTs were available (circles). The contour plots estimate the likelihood of finding an observation in a particular part of the space from only the circles. The solid line represents the identity condition (i.e., no priming) between the two plotted conditions. Panels $A$ and $B$ compare the RTs of morphologically related conditions (A) and the corresponding baselines (B) for both transparent and opaque RTs. Panels C and D compare transparent $(C)$ and opaque (D) RTs to related and unrelated prime-target pairs. The vertical distance of each point to the solid identity line in Panels $C$ and $D$ represents the amount of priming. In the four panels, the present experiment falls well within the normal pattern of spread of the previously published ones, independently of how they are compared. 
experiments of Marslen-Wilson et al. (2008), where latencies were atypically faster. Importantly, if transparency had no effect, one would expect to find an approximately equal number of experiments exhibiting greater facilitation for transparent and for opaque pairs in Figures 1C-1D. Not only is this not the case, but even without considering the present experiment, transparent facilitation is greater than opaque facilitation in 12 out of 16 published experiments. If we did exclude the three experiments that behave as outliers with respect to the published literature, this would reduce to 11 out of 13 experiments $(85 \%)$ that show more facilitation for transparent than for opaque pairs. This would increase to 12 out of 14 if we included the present data. In summary, on the basis of objective criteria, the collective pattern cannot be interpreted as support for equivalent amounts of facilitation for transparent and for opaque pairs.

In our materials, both LSA cosine values and participant ratings of relatedness predicted facilitation $[r(57)=$ $.14, p=.30$, and $r(71)=.32, p=.006$, respectively]. ${ }^{6}$ Therefore, one factor that may contribute to the failure to detect early effects of semantics is the extent of gradation in transparency. We suspect that the failure of Rastle et al. (2004) to observe an effect of transparency on facilitation latencies reflects attenuated differences in semantic transparency between transparently and opaquely related pairs, perhaps in conjunction with factors such as inconsistent matching of affix properties (length [the percentage of the prime repeated in the target], productivity) between related and unrelated primes for transparent and opaque pairs. There are also other potentially relevant differences between the present experiment and those of Rastle et al. (2004). Regarding the attributes of the targets used here as contrasted with those used in Rastle et al. (2004), the present targets were slightly shorter (averages of 4.04 vs. 4.86), had larger orthographic neighborhoods (averages of 11.82 vs. 2.18 ), and had slightly different morphological family sizes (the present transparent targets had larger family sizes [4.46 vs. 3.38], and the present opaque targets had slightly smaller family sizes [2.59 vs. 3.40$]$ ). Finally, as was discussed in the introduction, we included ID filler trials to increase the relatedness proportion above .50 in the present experiment, since the introduction of ID trials enhances semantic facilitation in masked priming tasks (e.g., Bodner \& Masson, 2003; Feldman \& BasnightBrown, 2008). In contrast, Rastle et al. (2004) included unrelated filler trials that reduced the relatedness proportion below .50. In essence, the present procedure created conditions favorable to observing semantic processing, whereas Rastle et al.'s (2004) procedure induced conditions that would make semantic processing more difficult to detect. Finally, we increased the proportion of nonword primes that shared a form with their targets in order to make form-similar word-nonword pairs comparable to form-similar word-word pairs, whereas Rastle et al.'s (2004) stimuli included only unrelated nonword targets. The implication is that, in the latter study, orthographic overlap predicted target lexical status, which may have encouraged the participants to base word decisions on shared form. This too could have contributed to the null effect between transparent and opaque facilitation in Rastle et al. (2004).

The present findings highlight another issue that is often overlooked. When data from multiple experiments on the same question are available, it is preferable to combine the evidence provided by each, rather than looking at them as a series of separate $p$ values. In the present context, the observation that any specific experiment failed to reach significance obscures the more general pattern that the majority of experiments showed small effects of transparency. For instance, Rastle and Davis (2008) provided a qualitative but no quantitative (statistical) summary of the previously published studies on the interaction between semantic relatedness and masked priming, concluding that most studies do not show the effect. Our quantitative assessment of the same data produces the opposite conclusion. The present experiment has confirmed this interpretation. Two findings are critical: Targets with opaque morphological relatives produced statistically reduced morphological facilitation relative to transparent pairs, and those stems had overall slower RTs. Future work will elaborate on the underlying reasons for these results.

\section{AUTHOR NOTE}

We thank Jessica Goldberg, Michael Morreale, Lindsey Masica, Momoko Okura, Liz Joyce, and Nader Manavizadeh for help with data collection. The research reported here was supported by National Institute of Child Health and Development Grant HD-01994 to Haskins Laboratories. Correspondence concerning this article should be sent to L. B. Feldman, Haskins Laboratories, 300 George Street, New Haven, CT 06511 (e-mail: 1f503@albany.edu).

\section{REFERENCES}

BAAYen, R. H. (2007a). Analyzing linguistic data: A practical introduction to statistics using $R$. Cambridge: Cambridge University Press.

BAAYEN, R. H. (2007b). Storage and computation in the mental lexicon. In G. Jarema \& G. Libben (Eds.), Mental lexicon core perspectives (pp. 81-104). Amsterdam: Elsevier.

BaAyen, R. H., Davidson, D. J., \& Bates, D. M. (2008). Mixed-effects modeling with crossed random effects for subjects and items. Journal of Memory \& Language, 59, 390-412. doi:10.1016/j.jml.2007.12.005

BAAYen, R. H., Wurm, L. E., \& AyCock, J. (2007). Lexical dynamics for low-frequency complex words: A regression study across tasks and modalities. Mental Lexicon, 2, 419-463.

Balota, D. A., YaP, M. J., Cortese, M. J., Hutchison, K. A., Kessler, B., Loftis, B., ET AL. (2007). The English Lexicon Project. Behavior Research Methods, 39, 445-459.

Bentin, B., \& Feldman, L. B. (1990). The contribution of morphological and semantic relatedness to repetition priming at short and long lags: Evidence from Hebrew. Quarterly Journal of Experimental Psychology, 42A, 693-711.

Bertram, R., Schreuder, R., \& BaAyen, R. H. (2000). The balance of storage and computation in morphological processing: The role of word formation type, affixal homonymy, and productivity. Journal of Experimental Psychology: Learning, Memory, \& Cognition, 26, 489511. doi:10.1037/0278-7393.26.2.489

Bodner, G. E., \& Masson, M. E. J. (2003). Beyond spreading activation: An influence of relatedness proportion on masked semantic priming. Psychonomic Bulletin \& Review, 10, 645-652.

Devlin, J. T., Jamison, H. L., Matthews, P. M., \& Gonnerman, L. M. (2004). Morphology and the internal structure of words. Proceedings of the National Academy of Sciences, 101, 14984-14988.

Diependaele, K., Sandra, D., \& Grainger, J. (2005). Masked crossmodal morphological priming: Unraveling morpho-orthographic and 
morpho-semantic influences in early word recognition. Language \& Cognitive Processes, 20, 75-114. doi:10.1080/01690960444000197

Feldman, L. B., Barac-Cikoja, D., \& Kostić, A. (2002). Semantic aspects of morphological processing: Transparency effects in Serbian. Memory \& Cognition, 30, 629-636.

Feldman, L. B., \& Basnight-Brown, D. B. (2008). List context fosters semantic processing: Parallels between semantic and morphological facilitation when primes are forward masked. Journal of Experimental Psychology: Learning, Memory, \& Cognition, 34, 680-687. doi:10.1037/0278-7393.34.3.680

Feldman, L. B., \& Soltano, E. G. (1999). Morphological priming: The role of prime duration, semantic transparency, and affix position Brain \& Language, 68, 33-39. doi:10.1006/brln.1999.2077

Feldman, L. B., Soltano, E. G., Pastizzo, M. J., \& Francis, S. E. (2004). What do graded effects of semantic transparency reveal about morphological processing? Brain \& Language, 90, 17-30. doi:10.1016/S0093-934X(03)00416-4

FoRSTER, K. I., \& AZUMA, T. (2000). Masked priming for prefixed words with bound stems: Does submit prime permit? Language \& Cognitive Processes, 15, 539-561. doi:10.1080/01690960050119698

Forster, K. I., Davis, C., Schoknecht, C., \& Carter, R. (1987). Masked priming with graphemically related forms: Repetition or partial activation? Quarterly Journal of Experimental Psychology, 39A, 211-251.

Forster, K. I., Mohan, K., \& Hector, J. (2003). The mechanics of masked priming. In S. Kinoshita \& S. J. Lupker (Eds.), Masked priming: The state of the art (pp. 3-37). New York: Psychology Press.

Jacobs, A. M., Grainger, J., \& Ferrand, L. (1995). The incremental priming technique: A method for determining within-condition priming effects. Perception \& Psychophysics, 57, 1101-1110.

Kazanina, N., Dukova-Zheleva, G., Geber, D., Kharlamov, V., \& Tonciulescu, K. (2008). Decomposition into multiple morphemes during lexical access: A masked priming study of Russian nouns. Language \& Cognitive Processes, 23, 800-823. doi:10.1080/01690960701799635

KUČERA, H., \& FrANCIS, W. N.(1967). Computational analysis of presentday American English. Providence, RI: Brown University Press.

Landauer, T. K., Foltz, P. W., \& Laham, D. (1998). An introduction to latent semantic analysis. Discourse Processes, 25, 259-284.

Lavric, A., Clapp, A., \& Rastle, K. (2007). ERP evidence of morphological analysis from orthography: A masked priming study. Journal of Cognitive Neuroscience, 19, 866-877. doi:10.1162/ jocn.2007.19.5.866

Longtin, C.-M., Segui, J., \& Halle, P. A. (2003). Morphological priming without morphological relationship. Language \& Cognitive Processes, 18, 313-334. doi:10.1080/01690960244000036

Lund, K., \& Burgess, C. (1996). Producing high-dimensional semantic spaces from lexical co-occurrence. Behavior Research Methods, Instruments, \& Computers, 28, 203-208.

Marslen-Wilson, W. D., Bozic, M., \& Randall, B. (2008). Early decomposition in visual word recognition: Dissociating morphology, form, and meaning. Language \& Cognitive Processes, 23, 394-421. doi:10.1080/01690960701588004

Marslen-Wilson, W. D., Tyler, L. K., Waksler, R., \& Older, L. (1994). Morphology and meaning in the English mental lexicon. Psychological Review, 101, 3-33. doi:10.1037/0033-295X.101.1.3

McCormick, S. F., Rastle, K., \& Davis, M. H. (2008). Is there a 'fete' in 'fetish'? Effects of orthographic opacity on morpho-orthographic segmentation in visual word recognition. Journal of Memory \& Language, 58, 307-326. doi:10.1016/j.jml.2007.05.006

Milin, P., Filipović Durdević, D., \& Moscoso del Prado Martín, F. (2009). The simultaneous effects of inflectional paradigms and classes on lexical recognition: Evidence from Serbian. Journal of Memory \& Language, 60, 50-64. doi:10.1016/j.jml.2008.08.007

Morris, J., Frank, T., Grainger, J., \& Holcomb, P. J. (2007). Semantic transparency and masked morphological priming: An ERP investigation. Psychophysiology, 44, 506-521. doi:10.1111/j.1469 -8986.2007.00538.x

Moscoso del Prado Martín, F. (2007). Co-occurrence and the effect of inflectional paradigms. Lingua e Linguaggio, 2, 247-262.

Plaut, D. C., \& Gonnerman, L. M. (2000) Are non-semantic morphological effects incompatible with a distributed connectionist approach to lexical processing? Language \& Cognitive Processes, 15, 445-485. doi:10.1080/01690960050119661

Pulvermüller, F., Assadollahi, R., \& Elbert, T. (2001). Neuromagnetic evidence for early semantic access in word recognition. European Journal of Neuroscience, 13, 201-205. doi:10.1046/j.0953 -816X.2000.01380.X

Pulvermüller, F., Shtyrov, Y., \& Ilmoniemi, R. J. (2003). Spatiotemporal dynamics of neural language processing: An MEG study using minimum-norm current estimates. NeuroImage, 20, 1020-1025. doi:10.1016/S1053-8119(03)00356-2

Rastle, K., \& Davis, M. H. (2003). Reading morphologically complex words: Some thoughts from masked priming. In S. Kinoshita \& S. J. Lupker (Eds.), Masked priming: The state of the art (pp. 279-305). New York: Psychology Press.

Rastle, K., \& Davis, M. H. (2008). Morphological decomposition based on the analysis of orthography. Language \& Cognitive Processes, 23, 942-971. doi:10.1080/01690960802069730

Rastle, K., Davis, M. H., Marslen-Wilson, W. D., \& Tyler, L. K. (2000). Morphological and semantic effects in visual word recognition: A time-course study. Language \& Cognitive Processes, 15, 507537. doi:10.1080/01690960050119689

Rastle, K., Davis, M. H., \& New, B. (2004). The broth in my brother's brothel: Morpho-orthographic segmentation in visual word recognition. Psychonomic Bulletin \& Review, 11, 1090-1098.

RUECKL, J. G., \& AICHER, K. A. (2008). Are CORNER and BROTHER morphologically complex? Not in the long term. Language \& Cognitive Processes, 23, 972-1001. doi:10.1080.01690960802211027

\section{NOTES}

1. The amount of letter overlap between the unrelated primes and their respective targets in the transparent versus opaque conditions was matched. Specifically, $31 \%$ of the target letters in each condition appeared in any position within the unrelated primes (on average, for a target of average letter length of about 4 , about 1.23 letters were in that transparent target's unrelated prime, and about 1.3 letters were in its opaque prime).

2 . In the rating task, the participants viewed the 80 related primetarget pairs, as well as the Rastle et al. (2004) materials, and "estimated how closely related the meanings of the two words are" on a 7-point Likert scale (higher indicating greater relatedness). The ratings appear in Table 2.

3. The significant effects reported in the Results section were also significant and of the same direction when the raw RTs (excluding correct RTs longer than $1,800 \mathrm{msec}$ ) were analyzed.

4. These results were also confirmed using a linear mixed-effects model regression (cf. Baayen et al., 2008) on the log-transformed RT, including random effects of participant and target identity, and fixed effects of log frequency, log morphological family size, relatedness, and stem type. The RTs also were analyzed with a linear mixed-effects model fitted to the log-transformed RTs, including fixed effects of log target frequency, log family size, relatedness, and an interaction between relatedness and transparency, taking into account the random effects of target and participant. Outlier detection after model criticism (cf. Baayen, 2007a) resulted in the exclusion of $4.6 \%$ of the trials that produced either model residuals or model-fitted values more extreme than $2.5 \mathrm{SDs}$. The resulting model revealed significant main effects of target frequency $[\beta=-0.0249, t(5574)=3.87, p=.0001]$, a marginal effect of family size $[\beta=-0.0207, t(5574)=-1.85, p=.064]$, and no main effect of relatedness $[\beta$ (unrelated) $=0.0120, t(5574)=1.44, p=.15]$. Most important, relatedness interacted with transparency, such that facilitation was significant in the transparent $[\beta$ (related, transparent) $=-0.0636$, $t(5574)=-3.80, p=.0001]$ but not in the opaque $[\beta$ (unrelated, transparent $)=-0.0175, t(5574)=-1.05, p=.293]$ condition. The model estimated transparent facilitation to be $36 \mathrm{msec}(95 \% \mathrm{CI}=26-49)$, and opaque facilitation to be $8 \mathrm{msec}(95 \% \mathrm{CI}=3-18)$ on the median values of frequency and family size.

5. Three opaque pairs (butchery-BUTCH, classify-CLASS, and banishBAN) were excluded from all analyses because of high ratings (4.61, 4.9, and 5.98 , respectively), but the transparency $\times$ prime type interaction was significant even with these items included.

6. Many items were missing LSA values, whereas all of the items had ratings. 
APPENDIX

Stimuli Used in the Critical Prime-Target Pairs of the Present Experiment

\begin{tabular}{|c|c|c|c|c|c|}
\hline \multicolumn{3}{|c|}{ Transparent Condition } & \multicolumn{3}{|c|}{ Opaque Condition } \\
\hline Target & $\begin{array}{l}\text { Related } \\
\text { Prime }\end{array}$ & $\begin{array}{c}\text { Unrelated } \\
\text { Prime }\end{array}$ & Target & $\begin{array}{l}\text { Related } \\
\text { Prime }\end{array}$ & $\begin{array}{c}\text { Unrelated } \\
\text { Prime }\end{array}$ \\
\hline adorn & adornment & ailment & amen & amenity & purity \\
\hline anger & angry & weary & $\operatorname{ban}^{\dagger}$ & banish & elfish \\
\hline bake & bakery & nursery & base & basement & pigment \\
\hline beep & beeper & eraser & batter & battery & blotchy \\
\hline block & blockade & lemonade & beak & beaker & dryer \\
\hline box & boxer & shaver & bee & beery & factory \\
\hline bride & bridal & frontal & bit & bitter & layer \\
\hline bury & burial & racial & bliss & blistery & eatery \\
\hline cool & coolant & pleasant & brig* & brigade & parade \\
\hline copy & copier & jailer & butch $^{\dagger}$ & butchery & mastery \\
\hline cord & cordless & mindless & butt & buttery & sorcery \\
\hline cure & curable & adorable & cape & capable & affable \\
\hline defy & defiant & reliant & carp $^{*}$ & carpal & feudal \\
\hline devote & devotion & deletion & cell & celery & creamery \\
\hline $\operatorname{dim}$ & dimmish & impish & class $^{\dagger}$ & classify & solidify \\
\hline dine & dinner & healer & clove & cloven & lessen \\
\hline drape & drapery & peppery & club & clubable & mixable \\
\hline dry & driest & closest & coin & coyness & baldness \\
\hline dust & dustless & meatless & $\operatorname{con}^{*}$ & condom & random \\
\hline eject & ejection & oration & core & coral & hymnal \\
\hline fork & forkless & timeless & cow & cower & roofer \\
\hline gas & gasify & codify & crate & crater & voter \\
\hline hill & hilly & dully & cute & cuttable & sizeable \\
\hline icy & iciness & kindness & den & denial & medial \\
\hline jury & jurist & pianist & dent & dentist & elitist \\
\hline $\operatorname{lax}^{*}$ & laxity & oddity & dorm & dormant & occupant \\
\hline lime & limeade & stockade & doze & dozen & quicken \\
\hline mock & mockery & pottery & earl* & earless & aimless \\
\hline mute & muteness & oneness & earn & earnest & fastest \\
\hline pave & pavement & ointment & fig & figment & easement \\
\hline pink & pinkness & shyness & harp & harness & fairness \\
\hline ply & pliable & breakable & husk & huskiness & likeness \\
\hline ripe & ripen & freshen & iron & irony & equally \\
\hline row & rowable & taxable & list & listless & lawless \\
\hline rude & rudeness & loudness & pit & pitiless & hapless \\
\hline scare & scary & frilly & ramp & rampant & pursuant \\
\hline tone & tonal & global & relay & relation & rotation \\
\hline tough & toughen & gladden & sack & saccade & arcade \\
\hline wine & winery & bribery & trade & tradition & fruition \\
\hline wise & wisdom & chiefdom & wit & witness & lioness \\
\hline
\end{tabular}

*Trimmed because of excessive errors. †Trimmed because ratings indicated it was not opaque.

(Manuscript received April 8, 2008;

revision accepted for publication March 17, 2009.) 